\title{
Avaliação do Uso de Inoculantes Microbianos sobre a Qualidade Fermentativa e Nutricional da Silagem de Milho' ${ }^{1}$
}

\author{
Paulo Henrique Mazza Rodrigues 2, 5, Juliana Martins Ruzante ${ }^{3}$, Ana Lúcia Senatore ${ }^{3}$, \\ Félix Ribeiro de Lima ${ }^{2}, 5$, Laércio Melotti², Paula Marques Meyer ${ }^{4}$
}

\begin{abstract}
RESUMO - Foram ensilados os milhos AG 510 e AG 5011 (Agroceres), formando oito tratamentos: controle (sem inoculantes), Sil-All ${ }^{\circledR}$ (S. faecium, P. acidilactici, L. plantarum, amilase, hemicelulase e celulase), Silobac ${ }^{\circledR}$ (L. plantarum, S. faecium e Lactobacillus sp.) e Pioneer $1174{ }^{\circledR}$ (S. faecium e L. plantarum). Os silos utilizados foram confeccionados em baldes plástico (quatro repetições/tratamento), portando válvula “bunsen” para livre escape dos gases. Após 106 dias de armazenamento, os silos foram abertos e amostrados para análise da composição bromatológica e perfil fermentativo. Para os híbridos AG 510 e AG 5011, foram obtidas diferenças quanto aos teores de MS (35,26 vs. 44,06\%), PB (8,07 vs. 9,73\%), NIDA (19,04 vs. 24,76\% do N total), FDN (62,03 vs. 64,71\%), FDA (36,74 vs. 40,19\%), lignina (11,24 vs. 12,57\%), carboidratos solúveis (12,0 vs. 7,0\%), amido (27,04 vs. 24,46\%), pH (3,79 vs. 4,32), nitrogênio amoniacal (4,19 vs. 8,81\% do N total), ácido láctico (4,875 vs. 1,421\% da MS) e ácido acético (1,269 vs. 2,682\% da MS). O produto Pionner 1174 incrementou os teores de carboidratos solúveis no híbrido AG 510, mas não no híbrido 5011. Apenas no híbrido AG 510 houve diferenças nos teores de amido, tendo sido maior no tratamento Pioneer e intermediário no Silobac, em relação ao controle e ao Sil-All. O híbrido AG 510 apresentou melhor perfil fermentativo, quando comparado ao AG 5011, embora não fossem demonstrados efeitos dos inoculantes sobre esses parâmetros.
\end{abstract}

Palavras-chave: ácidos orgânicos, bactérias ácido-láticas, fermentação, Zea mays

\section{Evaluation of Microbial Inoculation on Nutritional and Fermentative Quality of Corn Silage}

\begin{abstract}
The corn hybrids AG 510 and AG 5011 (Agroceres) were ensiled in plastic experimental silos (four units/treatment), consisting of eight treatments: control (without inoculation), Sil-All ${ }^{\circledR}$ (S. faecium, P. acidilactici, L. plantarum, amylase, hemicellulase, and cellulase), Silobac ${ }^{\circledR}$ (L. plantarum, S. faecium, and Lactobacillus sp.), and Pioneer $1174{ }^{\circledR}$ (S. faecium and L. plantarum). Silos were opened 106 days after ensiling and sampled to proceed chemical analyses. AG 510 and AG 5011 hybrids differed for DM (35.26 vs. 44.06\%), CP (8.07 vs. 9.73\%), ADIN (19.04 vs. 24.76\% of total N), NDF (62.03 vs. 64.71\%), ADF (36.74 vs. $40.19 \%)$, lignin (11.24 vs. $12.57 \%$ ), water soluble carbohydrates (12.0 vs. 7.0\%), starch (27.04 vs. $24.46 \%)$, pH (3.79 vs. 4.32 ), amoniacal nitrogen (4.19 vs. $8.81 \%$ of total $\mathrm{N}$ ), lactic acid (4.875 vs. $1.421 \%$ of DM) and acetic acid (1.269 vs. $2.682 \%$ of DM). Pionner $1174{ }^{\circledR}$ increased watersoluble carbohydrate in AG 510 hybrid, but not in AG 5011. Inoculation with Pioneer and Silobac had the highest and the intermediate starch content, respectively, in relation to control and Sil-All in the AG 510 hybrid, but not in AG 5011 . AG 510 provided better fermentation pattern when compared to AG 5011, although inoculants showed no effects on those parameters.
\end{abstract}

Key Words: additives, ensiling, lactic acid bacteria, organic acids, Zea mays

\section{Introdução}

A qualidade da silagem de milho varia em função de fatores extrínsecos, como o manejo de confecção do silo, condições climáticas e microbiota epifítica (Mahanna, 1997), e intrínsecos, como teor de matéria seca e carboidratos solúveis, poder tampão, nitratos e outras substâncias nitrogenadas (Morais, 1995). Com o objetivo de minimizar as perdas decorrentes da ensilagem, otimizar o processo fermentativo, reduzir a deterioração aeróbia e aumentar o valor nutritivo, tem sido pesquisado o uso de inoculantes microbianos na ensilagem (Harrison \& Blauwiekel, 1994). A aplicação de inoculantes em silagem de milho aumentou a produção de lactato durante o início da fermentação (Sebastian et al., 1996; Kung et al., 1993) e a recuperação da matéria seca após a fermentação (Cleale et al., 1990; Ely et al., 1982; Combs et al.,

\footnotetext{
1 Projeto financiado pela Fundação de Amparo à Pesquisa do Estado de São Paulo (FAPESP).

2 Professor do Departamento de Nutrição e Produção Animal - FMVZ/USP, Av. Duque de Caxias Norte, 225 - CEP: 13630-000,

Pirassununga, SP. E.mail: pmazza@usp.br

3 Bolsista de Iniciação Científica (FAPESP)

${ }^{4}$ Instituto Brasileiro de Geografia e Estatística-IBGE.

${ }^{5}$ Bolsista Produtividade em Pesquisa - CNPq.
} 
1986; Soderlund et al., 1986), proporcionando maior estabilidade aeróbia (Dawson et al., 1998; Cleale et al., 1990) e aumento do desempenho animal (Meeske \& Basson, 1998; Cleale et al., 1990). Entretanto, a inoculação nem sempre produziu respostas consistentes ou resultados estatisticamente significativos (Higginbothan et al., 1998; Eichelberger et al., 1997; Chen et al., 1994; Bolsen et al., 1992; Luther, 1986; Shockey et al., 1985).

O presente trabalho foi conduzido com os objetivos de analisar e comparar os efeitos dos inoculantes microbianos disponíveis no mercado brasileiro, em relação às características bromatológicas e ao perfil fermentativo de dois híbridos de milho.

\section{Material e Métodos}

As silagens foram confeccionadas nas dependências do Departamento de Nutrição e Produção Animal da Faculdade de Medicina Veterinária e Zootecnia da Universidade de São Paulo (Campus de Pirassununga). Foram escolhidos os híbridos AG 510 e AG 5011, da empresa Agroceres, ambos precoces com alta produtividade em grãos, colhidos aos 97 dias pós-plantio, no estádio farináceo duro.

O material foi picado em fragmentos médios de $2,5 \mathrm{~cm}$. Para cada híbrido foram utilizados 16 baldes plásticos, com 252 mm de altura e 245 mm de diâmetro, e tampa superior portando válvula tipo "bunsen” para o livre escape dos gases. A compactação correspondeu à densidade média de $484 \mathrm{~kg} / \mathrm{m}^{3}$ de silagem para o AG 510 e $382 \mathrm{~kg} / \mathrm{m}^{3}$ de silagem para o AG 5011, sendo esta variação decorrente dos teores de matéria seca dos híbridos, o que dificultou o processo de compactação no híbrido AG 5011. Os baldes foram divididos em quatro grupos, sendo um controle e os outros três tratados com os inoculantes comerciais listados abaixo:

a) Sil-All $\AA_{\text {: }}$ produto à base de Streptococcus faecium, Pediococcus acidilactici e Lactobacillus plantarum, bem como amilase, hemicelulase e celulase, na dose de 10,0 mg por $\mathrm{kg}$ de forragem; o produto possui 8,0x10 10 unidades formadoras de colônia/g.

b) SiloBac $\AA$ : produto à base de L. plantarum, S. faecium e Lactobacillus sp. na dose de $2,0 \mathrm{mg}$ por $\mathrm{kg}$ de forragem; o produto possui $5,26 \times 10^{10}$ unidades formadoras de colônia/g.

c) Pioneer $1174 \AA$ : produto à base de $S$. faecium e L. plantarum na dose de $1,11 \mathrm{mg}$ por $\mathrm{kg}$ de forragem; o produto possui 9,0×10 10 unidades formadoras de colônia/g.

R. Bras. Zootec., v.33, n.3, p.538-545, 2004
Imediatamente após a picagem, foi realizada uma amostragem da forragem para posterior análise de matéria seca, proteína bruta (AOAC, 1980), fibra em detergente neutro, fibra em detergente ácido, nitrogênio insolúvel em detergente ácido (Van Soest \& Robertson, 1985), lignina permanganato (Van Soest, 1967), carboidratos solúveis (Silva, 1981), amido (Pereira \& Rossi, 1995), digestibilidade in vitro da matéria seca (Tilley \& Terry, 1963) e poder tampão (Tosi, 1973).

Após a abertura, realizada com 106 dias de armazenamento, as silagens retiradas de cada silo foram homogeneizadas. Uma amostra foi separada para determinação da matéria seca, proteína bruta, componentes da parede celular, carboidratos solúveis, amido, digestibilidade in vitro da matéria seca e poder tampão, de acordo com a metodologia descrita para a matéria original. Outra fração da amostra foi colocada em prensa manual para extração dos sucos, onde foram determinados o pH (medição em potenciômetro), o nitrogênio amoniacal (Foldager, 1977) e os ácidos orgânicos (Erwin et al., 1961).

O delineamento adotado foi um inteiramente casualizado com um arranjo fatorial de tratamentos do tipo $4 \times 2$, correspondendo a quatro tratamentos com inoculantes e dois híbridos estudados. A análise de variância separou como causas de variação efeito de inoculante, efeito de híbrido e interação. As médias foram comparadas pelo teste Tukey. Na presença de interação, a separação entre os tratamentos foi realizada dentro da variável híbrido de milho. Para todas as análises realizadas, foi utilizado um nível de significância de 5\%.

\section{Resultados e Discussão}

A caracterização das plantas de milho (AG 510 e AG 5011) está apresentada na Tabela 1. De forma geral, as culturas apresentaram características semelhantes e a principal diferença entre os híbridos está relacionada aos teores de MS e carboidratos solúveis, sendo que o maior teor de MS e o menor de carboidratos solúveis foram observados no AG 5011 e podem estar relacionados à ocorrência de uma doença, que levou à senescência precoce deste híbrido. Segundo Lavezzo et al. (1997) e Morais (1995), à medida que evolui o estádio fisiológico da planta, os teores de MS aumentam, o que pode ser responsável pela diminuição da concentração de carboidratos solúveis. 
Tabela 1 - Composição bromatológica dos híbridos utilizados para ensilagem ${ }^{1}$

Table 1 - Chemical composition of hybrids used for ensiling

\begin{tabular}{lccccccccc}
\hline Hibr. & MS & PB & FDN & FDA & Lig & Amido & CHOs & DIVMS & PT \\
Hybr. & DM & CP & NDF & ADF & Lig & Starch & WSC & IVDDM & BC \\
\hline AG 510 & 32,87 & 8,48 & 69,06 & 38,79 & 12,32 & 30,03 & 9,8 & 46,51 & 19,13 \\
AG5011 & 41,24 & 9,99 & 70,26 & 39,48 & 14,17 & 31,80 & 5,2 & 46,39 & 15,44 \\
\hline
\end{tabular}

${ }^{1}$ MS: matéria seca total (\%); PB: proteína bruta (\% MS); FDN: fibra em detergente neutro (\% MS); FDA: fibra em detergente ácido (\% MS); Lig.: lignina (\% MS); Amido (\% MS); CHOs: carboidratos solúveis (\% MS); DIVMS: digestibilidade in vitro da matéria seca (\% MS); PT: poder tampão (meq/100 g MS de forragem).

${ }^{1}$ DM: dry matter (\%); CP: crude protein (\% DM); NDF: neutral detergent fiber (\% DM); ADF: acid detergent fiber (\% DM); Lig: lignin (\% DM); Starch (\% DM); WSC: water-soluble carbohydrate (\% DM); IVDDM: in vitro digestibility of dry matter (\% DM); BC: buffering capacity (meq./100 g of DM).

Os resultados de composição bromatológica do material após o processo de ensilagem são apresentados na Tabela 2. Foram observados incrementos nos teores de MS de todas as silagens, após o processo de ensilagem, fato que também foi detectado por Luther (1986). Contrariando o presente achado, Zago (1991) explicou que o teor de matéria seca poderia diminuir com o processo de ensilagem, caso os compostos voláteis produzidos, como o etanol e outros, tivessem sido perdidos durante a avaliação da matéria seca, subestimando o teor de MS (Zago, 1991).

Quanto aos efeitos dos inoculantes sobre os teores de MS, observou-se que o Pioneer e o Sil-All aumentaram os teores desse parâmetro nos híbridos AG 510 e AG 5011, respectivamente. Estes resultados discordam parcialmente dos obtidos por Berto \& Mühlbach (1995) e Eichelberg et al. (1997), em que o uso de inoculantes provocou diminuição no teor de matéria seca nas silagens com teores de MS mais elevados, mas acarretou elevação nas silagens com teores de matéria seca mais baixos, sugerindo que uma silagem com teor de matéria seca mais baixo, quando tratada, tenha melhor conservação, já que a mesma se estabiliza com teor de matéria seca mais elevado.

As alterações observadas nos teores de PB, em função do uso dos inoculantes, dentro do híbrido AG 5011, poderiam ser explicadas, caso os valores de $\mathrm{N}-\mathrm{NH}_{3}$ apontassem para perdas de nitrogênio das amostras durante processo de secagem em estufa de ventilação forçada. No entanto, observando os efeitos dos inoculantes nesta variável, não se identificaram diferenças que pudessem corroborar essa explicação. Quanto ao NIDA, os efeitos de inoculantes e híbrido foram estatisticamente significativos, ocorrendo diferenças entre os tratamentos Sil-All e Pioneer. No entanto, não houve diferença entre o
Pioneer e o Controle, de forma que o uso de inoculantes não melhorou os valores de NIDA, quando comparado ao controle. O híbrido AG 510 apresentou níveis de NIDA inferiores ao AG 5011, porém ambos superiores a $15 \%$, o que, segundo Mahanna (1997), indica a ocorrência de alterações decorrentes do aquecimento excessivo do material antes e depois da ensilagem, resultando na formação de compostos de Maillard, que indisponibilizam as formas nitrogenadas ao ruminante. A formação destes compostos pode ser explicada pela prolongação da fase aeróbia do material, devido à demora na confecção dos silos, ou problemas na compactação, em função do alto teor de matéria seca do AG 5011. Problemas na compactação aumentam as perdas e os teores de NIDA formado (Mahanna, 1997). Os valores de NIDA encontrados no presente estudo são superiores aos encontrados por Morais (1995) e Cleale et al. (1990). Morais (1995) obteve para o material de alta MS, em média, $13,29 \%$ do $\mathrm{N}$ total para o tratado com inoculante e $10,4 \%$ do $\mathrm{N}$ total para o controle. Para o material de baixa MS esses valores foram, respectivamente, iguais a 10,7 e 11,7\% do N total. Já Cleale et al. (1990) observaram teores que variaram de $6,82 \%$ do $\mathrm{N}$ total para o controle e $7,69 \%$ do $\mathrm{N}$ total para o inoculado.

Os valores de FDN foram superiores a 55\%, o que é considerado alto para uma silagem de milho. Porém, de acordo com Morais (1995), plantas de origem tropical geralmente possuem valores maiores que plantas de clima temperado. Os valores de FDN foram semelhantes aos obtidos por Eichelberger et al. (1997) e Cleale et al. (1990), que observaram, respectivamente, teores de 61,43 e $62,01 \%$ da MS para o grupo controle e 62,54 e $60,07 \%$ da MS para o tratado com inoculante. Morais (1995) obteve 60,09 e $60,9 \%$ da MS para o inoculado, 56,4 e 55,3\% da MS

\section{R. Bras. Zootec., v.33, n.3, p.538-545, 2004}


para o controle no material com maior e menor teor de MS, respectivamente.

Entre os inoculantes utilizados, o único a possuir enzimas celulolíticas e hemicelulolíticas era o Sil-All. No entanto, no híbrido AG 5011, o teor observado de FDN, com este inoculante, não foi diferente do controle e do Silobac, sendo inferior ao do Pioneer. Também no híbrido AG 510 este inoculante não diferiu do Controle e do Silobac, mas o teor de FDN foi significativamente maior que o Pioneer. Redução dos teores de FDN, entre a planta original e a silagem, foi observada por Sanderson (1993) e Luther (1986), podendo ser explicada pela degradação da hemicelulose, por meio da ação de enzimas da própria planta ou da hidrólise ácida, relatada por Jones et al. (1992).

Quanto aos teores de carboidratos solúveis e amido, apenas no híbrido AG 510 foram observados efeitos dos inoculantes. Para o amido, os tratamentos Pioneer e Silobac apresentaram os maiores valores e para os carboidratos solúveis, o tratamento Pionner.

Tabela 2 - Composição bromatológica das silagens submetidas aos diferentes tratamentos ${ }^{1}$ Table 2 - Chemical composition of silages submitted to different treatments

\begin{tabular}{|c|c|c|c|c|c|c|c|c|c|c|}
\hline $\begin{array}{l}\text { Híbr. } \\
\text { Hybr. }\end{array}$ & $\begin{array}{l}\text { Inocul. } \\
\text { Inocul. }\end{array}$ & MS & $\begin{array}{l}\mathrm{PB} \\
C P\end{array}$ & NIDA & FDN & FDA & Lig & Amido & CHOs & DIVMS \\
\hline \multirow{5}{*}{510} & $\begin{array}{l}\text { Controle } \\
\text { Control }\end{array}$ & $34,72^{b}$ & 8,16 & 19,67 & $62,59^{\mathrm{ab}}$ & $38,61^{\mathrm{a}}$ & 9,68 & $22,94^{\mathrm{C}}$ & $11,0^{\mathrm{b}}$ & $47,12^{a}$ \\
\hline & Sil-All & $34,72^{b}$ & 8,04 & 19,55 & $63,61^{\mathrm{a}}$ & $37,63^{a b}$ & 10,23 & $23,40^{c}$ & $10,4^{\mathrm{b}}$ & $47,18^{a}$ \\
\hline & Silobac & $35,07^{b}$ & 7,95 & 17,94 & $62,66^{\mathrm{ab}}$ & $36,55^{b}$ & 12,38 & $28,01^{\mathrm{b}}$ & $12,4^{\mathrm{ab}}$ & $46,24^{b}$ \\
\hline & Pioneer & $36,53^{a}$ & 8,15 & 19,00 & $59,28^{\mathrm{b}}$ & $34,16^{\mathrm{C}}$ & 12,66 & $33,80^{\mathrm{a}}$ & $14,4^{\mathrm{a}}$ & $46,14^{b}$ \\
\hline & $\begin{array}{l}\text { Média } \\
\text { Mean }\end{array}$ & 35,26 & 8,07 & 19,04 & 62,03 & 36,74 & 11,24 & 27,04 & 12,0 & 46,67 \\
\hline \multirow{6}{*}{5011} & $\begin{array}{l}\text { Controle } \\
\text { Control }\end{array}$ & $43,63^{b}$ & $9,07^{\mathrm{b}}$ & 24,17 & $64,93^{\mathrm{ab}}$ & $39,13^{a b}$ & 13,05 & 23,29 & 7,4 & $46,40^{b}$ \\
\hline & Sil-All & $48,34^{\mathrm{a}}$ & $9,89^{a b}$ & 27,00 & $61,16^{\mathrm{b}}$ & $37,35^{b}$ & 12,08 & 27,17 & 7,8 & $46,99^{\mathrm{a}}$ \\
\hline & Silobac & $43,11^{\mathrm{b}}$ & $9,80^{\mathrm{ab}}$ & 24,80 & $66,28^{a b}$ & $42,52^{\mathrm{a}}$ & 13,11 & 23,36 & 6,5 & $46,46^{\mathrm{ab}}$ \\
\hline & Pioneer & $41,16^{\mathrm{b}}$ & $10,18^{\mathrm{a}}$ & 23,06 & $66,47^{a}$ & $41,78^{\mathrm{a}}$ & 12,19 & 24,02 & 6,3 & $46,37^{b}$ \\
\hline & Média & 44,06 & 9,73 & 24,76 & 64,71 & 40,19 & 12,57 & 24,46 & 7,0 & 46,57 \\
\hline & Mean & & & & & & & & & \\
\hline \multirow{8}{*}{$\begin{array}{l}\text { Média } \\
\text { Mean }\end{array}$} & Controle & 39,17 & 8,61 & $21,92^{\mathrm{ab}}$ & 63,76 & 38,87 & 11,37 & 23,11 & 9,2 & 46,76 \\
\hline & Control & & & & & & & & & \\
\hline & Sil-All & 41,53 & 8,96 & $23,27^{\mathrm{a}}$ & 62,39 & 37,49 & 11,15 & 25,28 & 9,1 & 47,08 \\
\hline & Silobac & 39,09 & 8,88 & $21,37^{\mathrm{ab}}$ & 64,47 & 39,54 & 12,69 & 25,69 & 9,5 & 46,35 \\
\hline & Pioneer & 38,84 & 9,17 & $21,03^{\mathrm{b}}$ & 62,88 & 37,97 & 12,43 & 28,91 & 10,4 & 46,24 \\
\hline & Média & 39,66 & 8,90 & 21,90 & 63,37 & 38,47 & 11,88 & 25,75 & 9,5 & 46,62 \\
\hline & Mean & & & & & & & & & \\
\hline & $\mathrm{CV}$ & 12,59 & 10,63 & 15,54 & 4,82 & 7,47 & 13,25 & 16,05 & 33,08 & 1,03 \\
\hline \multicolumn{11}{|c|}{$\begin{array}{l}\text { Análise de variância } \\
\text { Analysis of variance }\end{array}$} \\
\hline \multirow{3}{*}{$\begin{array}{l}\text { Prob. } \\
\text { Prob. }\end{array}$} & $\begin{array}{l}\text { Inocul. } \\
\text { Inocul. }\end{array}$ & 0,0003 & 0,0294 & 0,0382 & NS & 0,0359 & 0,0312 & 0,0005 & NS & 0,0001 \\
\hline & Híbr. & 0,0001 & 0,0001 & 0,0001 & 0,0022 & 0,0001 & 0,0030 & 0,0043 & 0,0001 & NS \\
\hline & $\begin{array}{l}\text { Interação } \\
\text { Interaction }\end{array}$ & 0,0001 & 0,0137 & 0,0940 & 0,0022 & 0,0001 & 0,0195 & 0,0001 & 0,0102 & 0,0159 \\
\hline
\end{tabular}

${ }^{1}$ MS: matéria seca total (\%); PB: proteína bruta (\% MS); NIDA: nitrogênio insolúvel em detergente ácido (\% do N total); FDN: fibra em detergente neutro (\% MS); FDA: fibra em detergente ácido (\% MS); Lig.: lignina (\% MS); amido (\% MS); CHOS: carboidratos solúveis (\% MS); DIVMS: digestibilidade in vitro da matéria seca (\% MS); CV: coeficiente de variação (\%); Prob.: probabilidades estatísticas para efeito de inoculante (Inocul.), híbrido (Híbr.) e interação; NS: não-significativo.

${ }^{1}$ DM: dry matter (\%); CP: crude protein (\% DM); ADIN: acid detergent insoluble nitrogen (\% of total N); NDF: neutral detergent fiber (\% DM); ADF: acid detergent fiber (\% DM); Lig: lignin (\% DM); Starch (\% DM); WSC: water-soluble carbohydrate (\% DM); DMIVD: dry matter in vitro digestibility (\% DM); CV: coefficient of variation (\%); Prob: statistical probability for effect of inoculant (Inocul.), hybrid (hybr.) and interaction: NS: not significant.

Colunas com letras sobrescritas diferentes dentro de híbrido diferem pelo teste Tukey (5\%).

Columns with different letters inside hybrid differ by Tukey test (5\%). 
Segundo Chen et al. (1994) e Kung et al. (1993), incrementos observados nos carboidratos solúveis pelo processo de ensilagem poderiam ser explicados pela presença de enzimas que, por serem capazes de hidrolisar os componentes da parede celular, aumentariam o substrato disponível para a fermentação lática. Por outro lado, durante a fermentação, o amido também sofre alterações promovidas pela acidificação, podendo apresentar maior degradação, formando glicose. Outra possibilidade seria a transformação mais eficiente dos açúcares em ácido lático, promovida com a utilização dos inoculantes, mesmo que isso não resultasse em maior concentração final desse metabólito.

Deve-se considerar que os valores finais de carboidratos solúveis representam a soma dos carboidratos inicialmente presentes (açúcares redutores e a fração da amilose solúvel em água) e aqueles liberados durante o período de armazenamento da forragem, subtraídos do que foi fermentado. Os fatores envolvidos no processo de fermentação, no que diz respeito à velocidade de redução do pH e produção final de ácidos, deveriam ser considerados conjuntamente para melhor compreensão dos valores finais de carboidratos solúveis e amido e da conservação destes nutrientes. Logo, pela simples observação da composição dos inoculantes é difícil explicar tais resultados, seja pela presença ou ausência de enzimas, seja pelos microorganismos utilizados.

O teor de lignina, antes ou após a ensilagem, foi bastante elevado, quando comparado aos dados da literatura. Morais (1995) encontrou teores variando de 6,29 para o tratado e 6,9\% da MS para o controle. Já Eichelberger et al. (1997) obtiveram, respectivamente, 5,61 para o controle e 5,52\% da MS para o tratado. Estes autores utilizaram a metodologia de lignina em ácido clorídrico, descrita por Van Soest (1967), para determinar a concentração de lignina na planta, enquanto no presente experimento foi utilizado o método permaganato, que resulta em valores maiores que os obtidos por aquele método. Embora tenha sido observada interação inoculante $\mathrm{x}$ híbrido para esta variável, não foi possível detectar diferenças entre inoculantes com o teste Tukey (5\%).

Os dados de perfil fermentativo das silagens são apresentados na Tabela 3. A atividade proteolítica foi maior no híbrido AG 5011, uma vez que este apresentou valores de $\mathrm{N}-\mathrm{NH}_{3}$ maiores que o AG 510. Este fato poderia ser explicado pela má compactação decorrente do alto valor da MS deste híbrido, que estaria contribuindo para a demora na queda do $\mathrm{pH}$, responsável por inibir a atividade dos microrganismos e enzimas proteolíticas. Segundo Mahanna (1997), os valores de $\mathrm{N}-\mathrm{NH}_{3}$ no AG 510 estão adequados para uma silagem de boa qualidade, ao contrário do AG 5011, que apresentou valores superiores a 5\%.

Não foram identificadas diferenças significativas entre os valores de $\mathrm{pH}$ do suco da silagem, de nitrogênio amoniacal, de ácidos orgânicos e etanol quanto ao efeito de inoculante, mas sim quanto ao efeito de híbrido. Os valores do AG 510 estão muito próximos dos obtidos por Kung et al. (1993) e Luther (1986) no que se refere a pH e ácido lático. As concentrações de ácido acético, obtidas por estes autores, também foram semelhantes às observadas nos híbridos AG 510 e AG 5011. Higginbothan et al. (1998), Kung et al. (1993), Cleale et al. (1990) e Luther (1986) não observaram a diminuição do pH da silagem, em função da inoculação, fato que concorda com os dados obtidos no presente experimento. Diferenças estatisticamente significativas também não foram identificadas para a concentração de ácido lático, em decorrência da presença de inoculantes, por Higginbothan et al. (1998), Chen et al. (1994) e Meeske \& Basson (1998). No entanto, em experimentos realizados por Combs et al. (1986) e Alli \& Baker (1982), a inoculação aumentou a concentração de ácido lático em 7 e 70\%, respectivamente, quando comparada ao controle. No presente experimento, os valores do pH também estavam dentro da faixa ótima para conservação da silagem, porém os valores do híbrido AG 5011 se mostraram um pouco elevados, quando comparados aos trabalhos de Vilela (1998) e Mahanna (1997).

Quanto ao efeito de híbrido, o AG 510 teve pH inferior ao AG 5011. As concentrações de ácido lático e de ácido acético foram, respectivamente, superiores e inferiores no AG 510, indicando melhor processo fermentativo para o primeiro híbrido. O menor teor de MS e a maior concentração de carboidratos solúveis do AG 510 poderiam explicar a maior concentração de ácido lático deste híbrido e, portanto, seu menor $\mathrm{pH}$, quando comparado ao AG 5011. O alto teor de MS do AG 5011 pode ter dificultado a compactação do material, assim como a baixa concentração de carboidratos solúveis pode não ter proporcionado substrato suficiente para a fermentação lática, dificultando a redução do pH. No entanto, em plantas com maior teor de matéria seca, 
menor teor de ácidos é necessário para redução do pH para valores que indicam boa conservação do material.

Segundo os critérios de Mahanna (1997) e Vilela (1998), as concentrações dos ácidos orgânicos (lático, acético, butírico e propriônico) e do etanol poderiam ser consideradas adequadas, principalmente para o AG 510, caracterizando silagens de bom perfil fermentativo. A impossibilidade de detectar diferenças estatísticas nestas variáveis entre as silagens tratadas com inoculantes pode estar relacionada aos altos coeficientes de variação obtidos.
As alterações obtidas com o uso de inoculantes foram mínimas do ponto de vista bromatológico e fermentativo. Porém, autores como Meeske \& Basson (1998), Kung et al. (1993) e Wohlt (1989), apesar de não terem encontrado diferenças significativas entre os tratamentos e o controle, ao avaliarem o desempenho animal, obtiveram resultados positivos no aumento do ganho de peso e do consumo de matéria seca. Já Morais (1995), Luther (1986) e Wittenberg et al. (1983) não detectaram incrementos significativos para os parâmetros citados. Jochmann et al. (1998)

Tabela 3 - Fermentação das silagens submetidas aos diferentes tratamentos ${ }^{1}$

Table 3 - Fermentation pattern of silages submitted to different treatments

\begin{tabular}{|c|c|c|c|c|c|c|c|c|c|}
\hline $\begin{array}{l}\text { Híbr. } \\
\text { Hybr. }\end{array}$ & $\begin{array}{l}\text { Inocul. } \\
\text { Inocul. }\end{array}$ & $\begin{array}{l}\mathrm{pH} \\
\mathrm{pH}\end{array}$ & $\begin{array}{l}\mathrm{N}-\mathrm{NH}_{3} \\
\mathrm{NH}_{3}-\mathrm{N}\end{array}$ & $\begin{array}{l}\mathrm{PT} \\
B C\end{array}$ & $\begin{array}{l}\text { Etanol } \\
\text { Ethanol }\end{array}$ & $\begin{array}{l}\text { Acético } \\
\text { Acetic }\end{array}$ & $\begin{array}{l}\text { Prop. } \\
\text { Prop. }\end{array}$ & $\begin{array}{l}\text { Butír. } \\
\text { Butyric }\end{array}$ & $\begin{array}{l}\text { Lático } \\
\text { Lactic }\end{array}$ \\
\hline \multirow{6}{*}{510} & $\begin{array}{l}\text { Controle } \\
\text { Control }\end{array}$ & 3,76 & 4,29 & 45,85 & 0,481 & 1,182 & 0,0063 & 0,0058 & 3,931 \\
\hline & Sil-All & 3,80 & 4,13 & 47,72 & 0,360 & 1,425 & 0,0086 & 0,0015 & 5,067 \\
\hline & Silobac & 3,80 & 4,33 & 43,81 & 0,442 & 1,364 & 0,0076 & 0,0033 & 5,727 \\
\hline & Pioneer & 3,78 & 4,01 & 42,75 & 0,484 & 1,107 & 0,0080 & 0,0025 & 4,775 \\
\hline & Média & 3,79 & 4,19 & 45,03 & 0,442 & 1,269 & 0,0077 & 0,0035 & 4,875 \\
\hline & Mean & & & & & & & & \\
\hline \multirow{6}{*}{5011} & Controle & 4,30 & 9,43 & 41,36 & 0,056 & 2,546 & 0,0095 & 0,0000 & 1,466 \\
\hline & $\begin{array}{l}\text { Control } \\
\text { Sil-All }\end{array}$ & 4,38 & 8,69 & 39,82 & 0,053 & 2,567 & 0.0087 & 0.0013 & 1001 \\
\hline & Silobac & 4,34 & 8,80 & 42,50 & 0,082 & 2,790 & 0,0120 & 0,0000 & 1,690 \\
\hline & Pioneer & 4,28 & 8,31 & 42,80 & 0,066 & 2,827 & 0,0100 & 0,0000 & 1,429 \\
\hline & Média & 4,32 & 8,81 & 41,62 & 0,064 & 2,682 & 0,0101 & 0,0003 & 1,421 \\
\hline & Mean & & & & & & & & \\
\hline \multirow{8}{*}{$\begin{array}{l}\text { Média } \\
\text { Mean }\end{array}$} & Controle & 4,03 & 6,86 & 43,61 & 0,269 & 1,864 & 0,0079 & 0,0029 & 2,698 \\
\hline & Control & & & & & & & & \\
\hline & Sil-All & 4,09 & 6,41 & 43,77 & 0,207 & 2,000 & 0,0087 & 0,0013 & 3,084 \\
\hline & Silobac & 4,07 & 6,57 & 43,15 & 0,262 & 2,077 & 0,0099 & 0,0016 & 3,709 \\
\hline & Pioneer & 4,03 & 6,16 & 42,77 & 0,275 & 1,967 & 0,0090 & 0,0013 & 3,102 \\
\hline & Média & 4,05 & 6,50 & 43,33 & 0,253 & 1,976 & 0,0089 & 0,0018 & 3,148 \\
\hline & Mean & & & & & & & & \\
\hline & $\mathrm{CV}$ & 6,99 & 37,05 & 6,79 & 81,14 & 50,42 & 46,91 & 138,72 & 71,50 \\
\hline \multicolumn{10}{|c|}{$\begin{array}{l}\text { Análise de variância } \\
\text { Analysis of variance }\end{array}$} \\
\hline \multirow{4}{*}{$\begin{array}{l}\text { Prob. } \\
\text { Prob. }\end{array}$} & Inocul. & NS & 0,0619 & NS & NS & NS & NS & NS & NS \\
\hline & $\begin{array}{l}\text { Inocul. } \\
\text { Híhr }\end{array}$ & ח 001 & 00001 & 00001 & 00001 & 00001 & NS & רחמחת & O 0001 \\
\hline & Hybr. & & & & & & 10 & & \\
\hline & $\begin{array}{l}\text { Interação } \\
\text { Interaction }\end{array}$ & NS & NS & 0,0025 & NS & NS & NS & 0,0657 & NS \\
\hline
\end{tabular}

${ }^{1} \mathrm{~N}-\mathrm{NH}_{3}$ : nitrogênio amoniacal (\% do $\mathrm{N}$ total); PT: poder tampão (meq/100 g MS de forragem); Etanol (\% MS); Acético (\% MS); Prop.: propiônico (\% MS); Butír.: butírico (\% MS); Lático (\% MS); CV: coeficientes de variação (\%); Prob.: probabilidades estatísticas para efeito de inoculante (Inocul.), híbrido (Híbr.) e interação; NS: não-significativo.

${ }^{1} \mathrm{NH}_{3}-\mathrm{N}$ : ammoniacal nitrogen (\% of total N); BC: buffering capacity (meq./100 g of DM); Ethanol (\% DM); Acetic (\% DM); Prop.: propionic (\% DM); Butyric (\% DM); Lactic (\% DM); CV: coefficient of variation (\%); Prob: statistical probability for effect of inoculant (Inocul.), hybrid (Hybr.) and interaction; NS: not significant.

Colunas com letras sobrescritas diferentes dentro de híbrido diferem pelo teste Tukey (5\%).

Columns with different letters inside hybrid differ by Tukey test (5\%). 
revisaram aproximadamente 60 trabalhos que utilizaram bactérias produtoras de ácido lático como inoculante microbiano e concluíram que, em função do pequeno número de trabalhos relacionados à silagem de milho, não seria possível estabelecer conclusões finais referentes aos efeitos do inoculante no desempenho animal e digestibilidade da fibra.

Segundo Jones et al. (1992), a resposta limitada das características finais do material ensilado à inoculação pode ser devida à quantidade de substrato insuficiente para o processo de fermentação. De acordo com Ely et al. (1982), a microbiota epifítica pode interferir no desempenho do inoculante, competindo pelo substrato. Outro fator considerado por Chen et al. (1994) seria o fato de existirem diferenças entre os silos de laboratório e os silos usados na prática, como o trincheira ou superfície, criando então uma dificuldade para se avaliarem adequadamente os resultados decorrentes de um tratamento, uma vez que silagens confeccionadas em minisilos recebem, muito provavelmente, compactação bem superior à de um silo comercial.

\section{Conclusões}

Os produtos Pioneer ${ }^{\circledR} 1174$ e Silobac ${ }^{\circledR}$ incrementaram os teores de amido e o Pioneer ${ }^{\circledR}$, os teores de carboidratos solúveis do híbrido AG 510, mas não do híbrido 5011. Nas condições deste experimento, o híbrido AG 510 ensilado apresentou melhor perfil fermentativo que o AG 5011.

\section{Agradecimento}

À Fundação de Amparo à Pesquisa do Estado de São Paulo (FAPESP), pelo financiamento do projeto; aos funcionários Everson Lázaro e Gilmar Botteon, pelo cuidado com a cultura; e aos técnicos Ari de Castro, Gilson de Godoy e Simi Robassini, pelas análises laboratoriais.

\section{Literatura Citada}

ASSOCIATION OF OFFICIAL ANALYTICAL CHEMISTS AOAC. Official methods of analysis. 10.ed. Washington, D.C.: 1980. 1015p.

ALLI, L.; BAKER, B.E. Effects of additives on latic acid production and water soluble carbohydrates in chopped corn and alfalfa. Journal of Dairy Science, v.65, n.5, p.14721478, 1982.

BERTO, J.L.; MÜHLBACH, P.R.F. Silagem de aveia preta no estádio vegetativo submetida a ação de inoculantes e ao efeito do emurchecimento. In: REUNIÃO ANUAL DA SOCIEDADE DE ZOOTECNIA, 32., 1995, Brasília. Anais... Brasília: Sociedade Brasileira de Zootecnia, 1995. p.338.

BOLSEN, K.K.; LIN, C.; BRENT, B.E. et al. Effect of silage additives on microbial succession and fermentation process of alfalfa and corn silages. Journal of Dairy Science, v.75, n.11, p.3066-3083, 1992.

CHEN, J.; STOKES, M.R.; WALLACE, C.R. Effects of enzimeinoculant systems on preservation and nutritive value of haycrop and corn silage. Journal of Dairy Science, v.77, n.1, p.501-512, 1994.

CLEALE, R.M.; FIRKINS, J.L.; Van DE BEEK, F. et al. Effect of inoculation of whole plant corn forage with Pediococcus acidilactici and Lactobacillus xylosus on preservation of silage and heifer growth. Journal of Dairy Science, v.73, n.1, p.711-718, 1990.

COMBS, D.K.; TESSMAN, N.J.; LARSEN, H.J. Effect of microbial inoculant on silage fermentation in large scale laboratory silos. Journal of Dairy Science, v.69, supl.1 (Abst), p.186, 1986.

DAWSON, T.E.; RUST, S.R.; YOKOYAMA, M.T. Improved fermentation and aerobic stability of ensiled high moisture corn with the use of Propionibacterium acidipropionici. Journal of Dairy Science, v.81, n.4, p.1015-1021, 1998.

EICHELBERGER, L.; SIEWERDT, L.; SILVEIRA JR., P. Efeitos da inclusão de níveis crescentes de forragem de soja e uso de inoculantes na qualidade da silagem de milho. Revista Brasileira de Zootecnia, v.26, n.5, p.867-874, 1997.

ELY, L.O.; SUDWEEKS, E.M.; MOON, N.J. Chemical evaluation of Lactobacillus addition to alfalfa, corn, sorghum and wheat forage at ensiling. Journal of Dairy Science, v.65, n.4, p.1041-1046, 1982.

ERWIN, E.S.; MARCO, G.J.; EMERY, E.M. Volatile fatty acid analyses of blood and rumen fluid by gas chromatography. Journal of Dairy Science, v.44, n.9, p.1768-1771, 1961.

FOLDAGER, J. Protein requeriment and non protein nitrogen for high producing cow in early lactation. East Lasing: Michigan State University, 1977. 167p. Tese (Doutorado em Ciência Animal) - Michigan State University, 1977.

HARRISON, J.H.; BLAUWIEKEL, R. Fermentation and utilization of grass silage. Journal of Dairy Science, v.77, n.10, p.3209-3235, 1994.

HIGGINBOTHAN, G.E.; MUELLER, S.C.; BOLSEN, K.K. et al. Effects of inoculants cointaining propionic acid bacteria on fermentation and aerobic stability of corn silage. Journal of Dairy Science, v.81, n.8, p.2185-2193, 1998.

JOCHMANN, K.; LEBZIEN, P.; FLACHOWSKY, G. Influence of lactic acid bacteria as inoculant on rumen fermentation, digestibility of silages as well as on performance of dairy cows. Ubersichten-zur-Tierernahrung, v.26, n.1, p.123-155, 1998.

JONES, B.A.; HATFIELD, R.D.; MUCK, R.E. Effects of fermentation and bacterial inoculation on lucerne cell walls. Journal of Science Food Agriculture, v.60, n.2, p.147155, 1992.

KUNG JR., L.; CHEN, J.H.; KRECK, E.M. et al. Effect of microbial inoculants on the nutritive value of corn silage for lactating dairy cows. Journal of Dairy Science, v.76, n.12, p.3763-3770, 1993.

LAVEZZO, W. Silagem de capim-elefante. Informe Agropecuário, v.11, n.132, p.50-57, 1985.

LUTHER, R.M. Effect of microbial inoculation of whole plant 
corn silage on chemical characteristics, preservation and utilization by steers. Journal of Animal Science, v.63, n.5, p.1329-1336, 1986.

MAHANNA, B. Troubleshooting silage problems. Assessado em 20 de outubro de 1997. Disponível em http:// www.pioneer.com/xweb.

MEESKE, R.; BASSON, H.M. The effect of a lactic acid bacterial inoculant on maize silage. Animal Feed Science Technology, v.70, n.3, p.239-247, 1998.

MORAIS, J.P.G. Avaliação do efeito de inoculantes bacterianos sobre a qualidade de silagem e desempenho animal. Piracicaba: Escola Superior de Agricultura "Luiz de Queiroz”, 1989. 77p. Dissertação (Mestrado em Ciência Animal e Pastagens) - Escola Superior de Agricultura "Luiz de Queiroz”, 1995.

PEREIRA, J.R.A.; ROSSI JR., P. Manual prático de avaliação nutricional de alimentos. Piracicaba: Fundação de Estudos Agrários “Luiz de Queiroz”, 1995. 25p.

SANDERSON, M.A. Aerobic stability and in vitro fiber digestibility of microbially inoculated corn and sorghum silages. Journal of Animal Science, v.71, n.2, p.505-514, 1993.

SEBASTIAN, S.; PHILLIP, L.E.; FELLNER, V. et al. Comparative assessment of bacterial inoculation and propionic acid treatment on aerobic stability and microbial population of ensiled high-moisture ear corn. Journal of Animal Science, v.74, n.2, p.447-456, 1996.

SHOCKEY, W.L.; DEHORIRY, B.A.; CONRAD, H.R. Effects of microbial inoculant on fermentation of alfalfa and corn. Journal of Dairy Science, v.68, n.11, p.3076-3080, 1985.

SILVA, D.J. Análise de alimentos (Métodos químicos e biológicos). 1.ed. Viçosa, MG: Universidade Federal de Viçosa, 1981. 166p.

SODERLUND, S.D.; RICE, D.W.; HINDS, M.A. et al. Effects of Pioneer brand 1177 silage inoculant on nutrient preservation and feeding value of whole plant corn silage. Journal of Animal Science, v.63, supl.1 (Abstr.), p.289, 1986.
TILLEY, J.M.A.; TERRY, R.A. A two stage technique for the in vitro digestion of forage crops. Journal of British Grassland Society, v.18, n.2, p.104-111, 1963.

TOSI, H. Ensilagem de gramíneas tropicais sob diferentes tratamentos. Jaboticabal: Universidade Estadual de São Paulo, 1973. 107p. Tese (Doutorado) - Universidade Estadual de São Paulo, 1973.

Van SOEST, P.J. Development of a comprehensive system for analysis and its application to forage. Journal of Animal Science, v.26, n.1, p.119-128, 1967.

Van SOEST, P.J.; ROBERTSON, J.B. Analysis of forages and fibrous foods. 1.ed. Ithaca: Cornell University, 1985. 202p.

VILELA, D. Aditivos para silagem de plantas de clima tropical. In: REUNIÃO ANUAL DA SOCIEDADE BRASILEIRA DE ZOOTECNIA, 35., 1998, Botucatu. Anais... Botucatu: Sociedade Brasileira de Zootecnia, 1998. p.73-108.

WITTENBERG, K.M.; INGALLS, J.R.; DEVLIN, T.J. The effect of lactobacteria inoculation on corn silage preservation and feeding value for growing beef animals and lambs. Canadian Journal of Animal Science, v.63, n.4, p.917-925, 1983.

WOHLT, J.E. Use of silage inoculant to improve feeding stability and intake of a corn silage-grain diet. Journal of Dairy Science, v.72, n.2, p.545-551, 1989.

ZAGO, C.P. Cultura de sorgo para a produção de silagem de alto valor nutritivo. In: SIMPÓSIO SOBRE NUTRIÇÃO DE BOVINOS, 4., 1991, Piraciacaba. Anais... Piracicaba: Fundação de Estudos Agrários Luiz de Queiroz, 1991. p.169-213. 